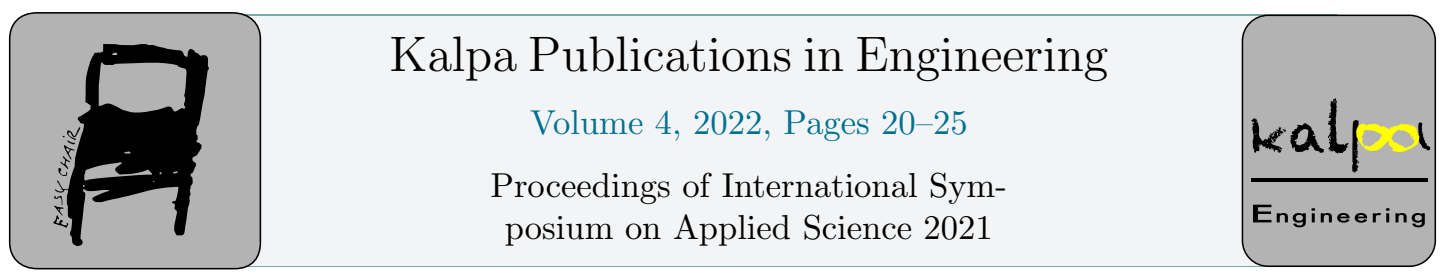

\title{
The Effect Of Low-Level Laser In The Growth And Biological Activities Of Bitter Melon
}

\author{
Mai Thuc Vy Huynh ${ }^{1,3}$, Thi Tien Pham ${ }^{1,3}$, My Nga Truong ${ }^{1,3}$ and Tran \\ Hong Duyen Trinh ${ }^{2,3, *}$ \\ ${ }^{1}$ Department of Biomedical Engineering Physics, Faculty of Applied Science, Ho Chi Minh City \\ University of Technology (HCMUT), 268 Ly Thuong Kiet Street, District 10, Ho Chi Minh City, \\ Vietnam \\ ${ }^{2}$ Laboratory of Laser Technology, Faculty of Applied Science, Ho Chi Minh City University of \\ Technology (HCMUT), 268 Ly Thuong Kiet Street, District 10, Ho Chi Minh City, Vietnam \\ ${ }^{3}$ Vietnam National University Ho Chi Minh City, Linh Trung Ward, Thu Duc District, Ho Chi \\ Minh City,Vietnam \\ *Corresponding author: tt_hd2005@hcmut.edu.vn
}

\begin{abstract}
Applying laser technology to the growth of plants to limit the use of chemical fertilizers is an interesting topic in agriculture. The main idea is to preserve the environment, ensuring product quality while still achieving high productivity, we decided to carry out this research project, to investigate the effect of the low-level laser (the wavelengths $532 \mathrm{~nm}, 850 \mathrm{~nm}$, and $940 \mathrm{~nm}$ ) on stems and leaf development. It is expected that with these research results, the implementation method will be widely disseminated in the high agricultural sector, coming closer to farmers. Moreover, the results of the analysis of the composition of bitter melon stems and leaves will be applied in medical treatment (such as diabetes, wound treatment, anti-oxidation, anti-bacteria ...).

Keywords: Bitter melon, Momordica charantia, Biological activities, Insulin, hyperglycemia.
\end{abstract}

\section{Introduction}

Today, using chemicals in agriculture is being abused. Pesticides, herbicides, stimulants, chemical fertilizers, ... everything related to plant protection chemistry if overused not only affects the health of consumers but righteousness farmers were the first to suffer. Therefore, clean agriculture that is researched and developed becoming important. We want to bring new technology that uses lasers to shine on seeds, and bitter melon trees in the development of plants to replace the habit of using pesticides, chemical fertilizers ... but still bring high efficiency to plants. 
In current medicine, diabetes is considered one of the top five causes of death in the world [1]. It is a metabolic disorder, often a combination of mobility and environmental personnel, leading to abnormally high internal sugar (hypertension) [2]. Since ancient times, suffering is considered a miracle that is still too strange to control diabetes in folk. So why does suffering have the ability of diabetic diabetics? The composition of the person responsible for the anti-pathway authors is triterpene, proteid, steroid, alkaloid, inorganic, lipid, and phenolic compounds. Several glycosides have been isolated from stems and results and grouped under cucurbitane-type triterpenoids. In particular, four triterpenoids with active protein kinase activated AMP is a base of the system serum under the system. Main compounds that were distributed from bitter melon and identified as the author of hypoglycemia included charatin, polypeptide-p, and vicine.

Charantin is a triterpenoid type cucurbitane in typical bitter melon and is a potent antidiabetic agent [3-4]. Pitiphanpong and co-workers have shown that charatin can be used to treat diabetes and potentially replace treatment [5]. It is a mixture of two compounds, namely sitosterol glucoside and stigmasterol glucoside [5]. Charantin from bitter melon fruit was extracted and estimated by highefficiency thin layer chromatography [6]. Polypeptide-p: In bitter melon contains polypeptide-p and is used to control diabetes naturally. Polypeptide-p or p-insulin is an insulin-like hypoglycemic protein, proven to be decreased blood sugar levels in rats, langurs, and humans when injected under the skin. Vicine: Another major compound that has been isolated from the seeds of the bitter melon is an alkaloid glycol called vicine [7]. This pyrimidine nucleoside has been shown to cause hypoglycemia in nondiabetic starving rats by intraperitoneal injection [8].

\section{Material}

Momordica charantia (M. Charantia), also known as bitter gourd, karela, and balsam pear, is a popular plant used to treat diabetes-related conditions in native populations of Asia, South America, India, the Caribbean. and East Africa [9-10]. Its fruit has a characteristic bitter taste, which is more bitter when ripe, hence the name bitter melon.

Bitter melon seeds: F1 CĐX 276. Chemical composition: Regarding nutritional composition, bitter melon contains $91.8 \%$ water, $0.20 \%$ lipid, $4.2 \%$ carbohydrates, and $1.4 \%$ fiber. Hydroponic water solution. Laser: Using wavelengths $532 \mathrm{~nm}, 850 \mathrm{~nm}, 940 \mathrm{~nm}$. The projection medium is surrounded by foil to limit the laser's absorption by the surrounding environment. The effect of lasers on plants.

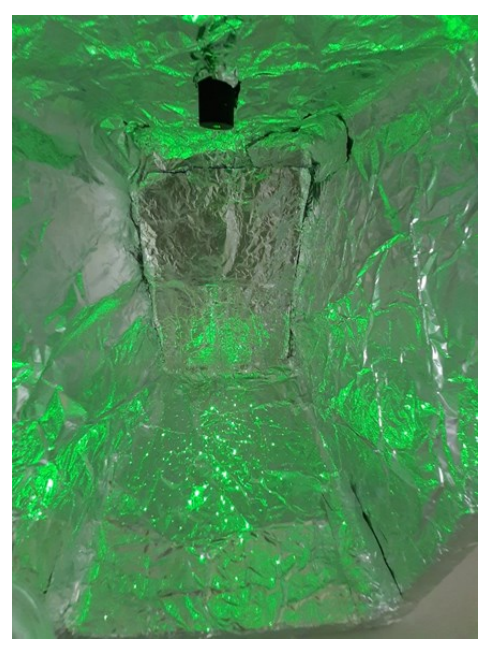


Figure 1: Experimental model of laser 532nm

\section{Method}

The research topic of the group is divided into 2 phases, performing experiments and comments after each stage

Stage 1: Hydroponic cultivation

- Target: surveying the height, roots, and size of the leaves in the first 4 cotyledons; analyzing experimental results.

- $\quad$ Planting time: 20 days (from December $7^{\text {th }}, 2020$, to December $26^{\text {th }}, 2020$ ).

- Divide the lot into 10 samples, numbered from 1 to 10 . They are described in Table 1:

\begin{tabular}{|l|l|l|l|l|}
\hline Exposure time & $532 \mathrm{~nm}$ & $850 \mathrm{~nm}$ & $940 \mathrm{~nm}$ & Control Group \\
\hline $5 \mathrm{~min}$ & $(1)$ & $(2)$ & $(3)$ & \multirow{2}{*}{$(10)$} \\
\cline { 1 - 4 } $10 \mathrm{~min}$ & $(4)$ & $(5)$ & $(6)$ & \multirow{2}{*}{} \\
\hline $20 \mathrm{~min}$ & $(7)$ & $(8)$ & $(9)$ & \\
\hline
\end{tabular}

Table 1: Experimental samples

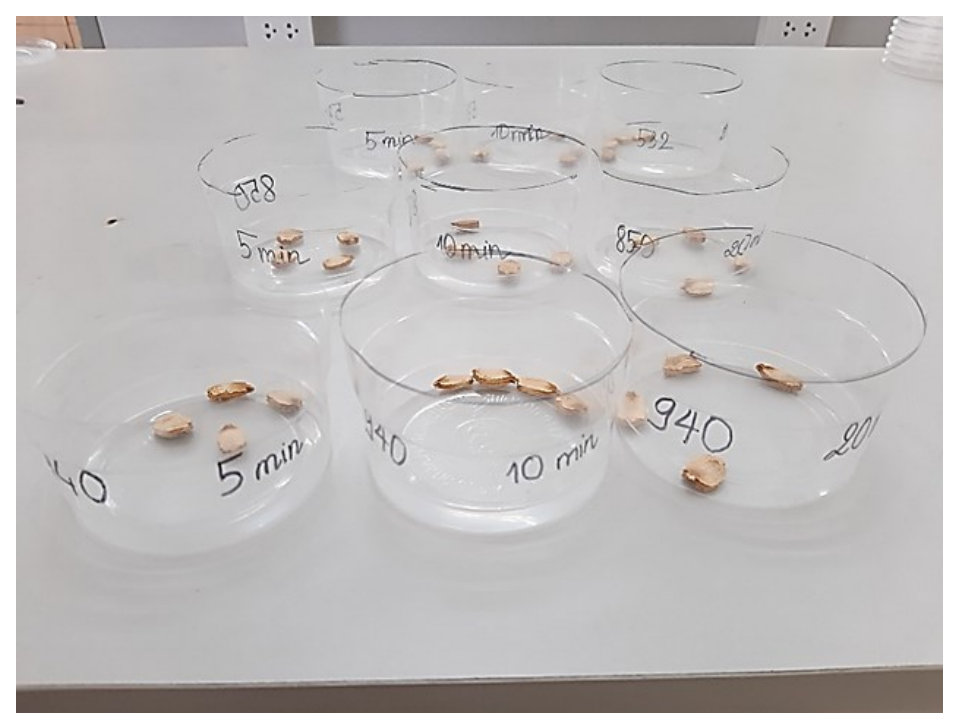

Figure 2: Melon bitter seeds F1 CDX276 are classified

In figure 2, seeds are lighted in 5 days $(7-11 / 12 / 2020)$ 


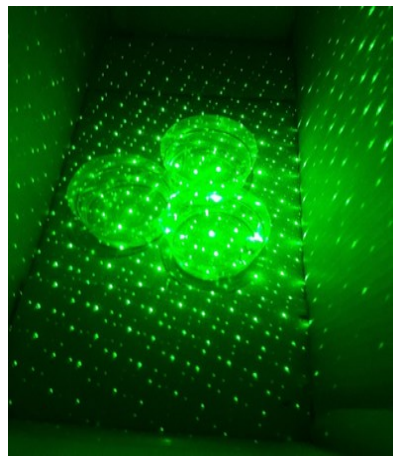

Figure 3: Laser 532nm on bitter melon seeds

The seeds are then kept in water for 6 hours (figure 3), then added to a hydroponic solution $(12 / 12 / 2020)$. Take care and get data for twice analyzing:

+ The first is day 16th (December 22, 2020)

+ The second day 20th (December 26, 2020). End of stage 1.

Stage 2: Planting the land, target:

+ Planting until the tree gives fruit, take samples to extract, analyze the components in the stem and leaves.

+ Analyze experimental results.

\section{Result and discussion}

After 20 days of taking care we get the following table 2 and table 3 :

\begin{tabular}{|l|l|l|l|l|}
\hline $\begin{array}{l}\text { Time } \\
22 / 12 / 2021\end{array}$ & Wavelength & Height $(\mathrm{cm})$ & $\begin{array}{l}\text { Length of } \\
\text { root }(\mathrm{cm})\end{array}$ & Area of the leaf $\left(\mathrm{cm}^{2}\right)$ \\
\hline 5 minutes & $532 \mathrm{~nm}$ & $13,5 \mathrm{~cm}$ & 6,5 & 8.75 \\
\cline { 2 - 5 } & $850 \mathrm{~nm}$ & $14,5 \mathrm{~cm}$ & 8 & $\mathbf{1 4 . 4}$ \\
\cline { 2 - 5 } & $940 \mathrm{~nm}$ & $8,5 \mathrm{~cm}$ & 8 & 6.6 \\
\hline \multirow{3}{*}{10 minutes } & $532 \mathrm{~nm}$ & $\mathbf{1 5}$ & 3 & 12.25 \\
\cline { 2 - 5 } & $850 \mathrm{~nm}$ & 10,5 & 6,5 & 7.5 \\
\cline { 2 - 5 } & $940 \mathrm{~nm}$ & 12 & 8 & 12 \\
\hline \multirow{3}{*}{20 minutes } & $532 \mathrm{~nm}$ & 8,5 & 7 & 11.4 \\
\cline { 2 - 5 } & $850 \mathrm{~nm}$ & 13,5 & 7,5 & $\mathbf{1 4 . 0 8}$ \\
\cline { 2 - 5 } & $940 \mathrm{~nm}$ & 12 & $\mathbf{9}$ & 12 \\
\hline & Control group & 15 & 7,5 & $\mathbf{1 7 . 5}$ \\
\hline
\end{tabular}

Table 2: Data for the first time survey

\begin{tabular}{|l|l|l|l|l|}
\hline $\begin{array}{l}\text { Time } \\
26 / 12 / 2021\end{array}$ & Wavelength & Height $(\mathrm{cm})$ & $\begin{array}{l}\text { Length of } \\
\text { root }(\mathrm{cm})\end{array}$ & Area of the leaf $\left(\mathrm{cm}^{2}\right)$ \\
\hline \multirow{3}{*}{5 minutes } & $532 \mathrm{~nm}$ & $14 \mathrm{~cm}$ & 7 & 13.5 \\
\cline { 2 - 5 } & $850 \mathrm{~nm}$ & $14,5 \mathrm{~cm}$ & 8 & $\mathbf{2 0}$ \\
\cline { 2 - 5 } & $940 \mathrm{~nm}$ & $10 \mathrm{~cm}$ & 8,5 & 12 \\
\hline \multirow{3}{*}{10 minutes } & $532 \mathrm{~nm}$ & 15 & 7,5 & 13.5 \\
\cline { 2 - 5 } & $850 \mathrm{~nm}$ & 10,5 & 8 & 9.8 \\
\cline { 2 - 5 } & $940 \mathrm{~nm}$ & 13 & 9 & 13.5 \\
\hline
\end{tabular}




\begin{tabular}{|l|l|l|l|l|}
\hline 20 minutes & $532 \mathrm{~nm}$ & 16 & 7 & 15.75 \\
\cline { 2 - 5 } & $850 \mathrm{~nm}$ & 14 & 8,5 & $\mathbf{2 4}$ \\
\cline { 2 - 5 } & $940 \mathrm{~nm}$ & 13,5 & 9 & 14.4 \\
\hline \multirow{3}{*}{} & $\begin{array}{l}\text { Control } \\
\text { group }\end{array}$ & 16 & 11 & $\mathbf{2 0}$ \\
\hline
\end{tabular}

Table 3: Data for the second time survey

Because at the next stage, we use leaves to do the extraction process to survey the components. Therefore, we choose the leaf area as the basis for analysis. Based on the leaf area, it can be seen that a low-level laser with a wavelength of $850 \mathrm{~nm}$ at 20 minutes has a positive effect on the development of bitter leaves compared to other wavelengths.

When low-level lasers are used in agriculture, it has shown a wide range of positive effects. Some studies [11] have shown the ability to promote the development of seeds, improve germination rate, plant growth, increase metabolism, and promote photosynthesis. This interaction resulted in increased chlorophyll and carotenoid content of the seedlings when subjected to low-level laser irradiation. In vegetable production, laser seed stimulation before sowing has increased the yield of several crops such as maize (from 10 to $15 \%$ ), wheat (20 to $30 \%$ ), barley (from 20 to 25 ). $\%$ ), beets (10 to $30 \%$ ), mustard seed $(10$ to $15 \%)$. Laser treatment before seeding affected the root and leaf yield and it reduced the $\mathrm{N}$, $\mathrm{P}, \mathrm{K}, \mathrm{Ca}$ content in the roots.

To visualize our results, construct a graph in figure 4 look like this:

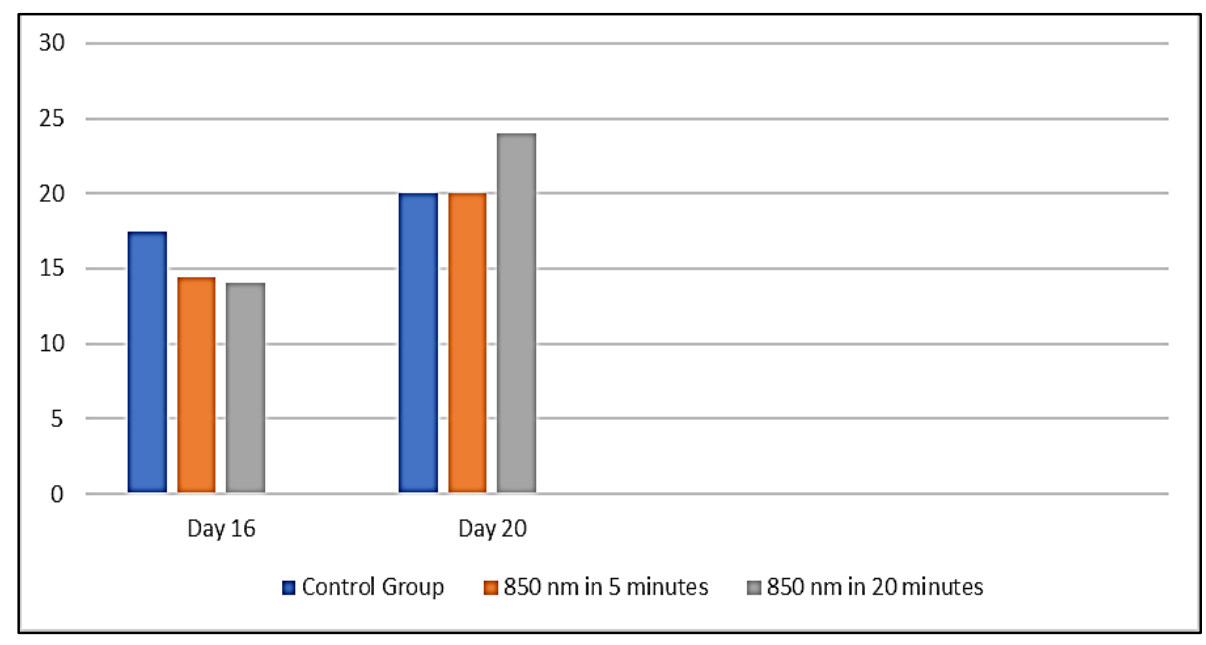

Figure 4: The effect of laser $850 \mathrm{~nm}$ in different times when compared to control group

From the above chart we can see that a low-level laser with a wavelength of $850 \mathrm{~nm}$ illuminated for 20 minutes has the effect of increasing the leaf area by $20 \%$ compared to the control plants.

\section{Conclusion}

Experimental study on the interaction of semiconductor low-level laser beams working at different wavelengths on bitter melon trees - laser working at $850 \mathrm{~nm}$ wavelength at 20 minutes, obtained the results: 
+ The leaf area increases considerably compared to leaf areas that were lighted at $532 \mathrm{~nm}$ and $940 \mathrm{~nm}$.

+ Bitter melons lighted with $850 \mathrm{~nm}$ wavelength is the most verdant in all experimental groups.

\section{Conflicts of Interest}

The authors declare no conflicts of interest.

\section{Acknowledgment}

This research is funded by Ho Chi Minh City University of Technology (HCMUT) - VNUHCM under grant number SVCQ - KHUD - 2020 - 39. We would like to thank Ho Chi Minh City University of Technology (HCMUT) - VNUHCM for the support of time and facilities for this study. The authors declare that they have no conflict of interest.

\section{References}

[1] Joseph B, Jini D. (2011). Insight into the Hypoglycaemic Effect of Traditional Indian Herbs used in the Treatment of Diabetes. Research Journal of Medicinal Plant 5 (4). $352-376$.

[2] Patel DK, Prasad SK, Kumar R, Hemelatha S. (2012). An overview of antidiabetic medicinal plants having insulin-mimetic properties. Asian Pacific Journal of Tropical Biomedicine. 320-330.

[3] Krawinkel MB, Keding GB.(2006) Bitter Gourd (Momordica charantia): A Dietary Approach to Hyperglycemia. Nutrition Review. 331-337

[4] Patel S, Patel T, Parmar K, Bhatt Y, Patel Y, Patel NMD. (2010) Isolation, Characterization And Antimicrobial Activity Of Charantin From Momordica Charantia Linn. Fruit. Int J Medical. Deve Res; 629-634

[5] Pitiphanpong J, Chitprasert S, Goto M, Jiratchariyakul W, Sasaki M, Shotipruk A. (2010). A new approach for extraction of charantin from Momordica charantia with pressurized liquid extraction. Separation and Purification Technology 52. 416-422

[6]Thomas CT, Reddy PY, Devanna N.(2012). Impact of cooking on charantin estimated from bitter melon fruits using high-performance thin-layer chromatography. Int Res J Pharm. 149-154.

[7] Haixia Z, Xiaozuo Z, Yawei W, Mancanq L, Zhide H.(2004). Analysis of vicine in bitter melon samples by polyglycol-C8 solid phase with high-performance liquid chromatography. Chin J Anal Chem.48-108.

[8] Ham C, Wang J.(2009). Optimization of conditions for charantin extraction in PEG/salt aqueous two-phase systems using response surface methodology. Open Compl Med J. 46-50

[9] Cefalu WT, Ye J, Wang ZQ. (2008). Efficacy of dietary supplementation with botanicals on carbohydrate metabolism in humans. Endocr Metab Immune Disord Drug Targets. 78-81.

[10]Cousens G. (2008). There is a cure for diabetes: the tree of life 21-day program. California: North Atlantic Books. 191-192.

[11] A.C. Hernamdez, P.A. Domiguez, O.A. Cruz, R. Ivanov, C.A.Carballo, B.R.Zepeda. (2010). Laser in agriculture. Int.Agrophys. $407-422$. 